\title{
Nosocomial Infections in Patients with Traumatic Brain Injury: A Hospital-Based Study from North India
}

\author{
Ajaz Koul ${ }^{1} \quad$ Arif Sheikh ${ }^{1}$ Sajad Bhat ${ }^{1} \quad$ Abrar Ahad $^{2} \quad$ Ruhail Qadir $^{1} \quad$ Nayl Khurseed ${ }^{2}$ Raja Kamil ${ }^{1}$ \\ ${ }^{1}$ Department of Medicine \& Infection Diseases, Sher-i-Kashmir \\ Institute of Medical Sciences, Soura, Srinagar, Kashmir, India \\ ${ }^{2}$ Department of Neurosurgery, Sher-i-Kashmir Institute of Medical \\ Sciences, SKIMS, Soura, Srinagar, Kashmir, India

\begin{abstract}
Address for correspondence Ajaz Koul, MD, FRCP, Department of Medicine \& Infectious Diseases, Sher-i-Kashmir Institute of Medical Sciences, Soura, Srinagar 190011, Kashmir, India (e-mail: ajazkoul@yahoo.com).
\end{abstract}

Indian J Neurosurg 2021;10:216-219.

\begin{abstract}
Keywords

- traumatic brain injury

- nosocomial infections

- infections

Background Traumatic brain injury (TBI) is a major global health concern, it being a leading cause of morbidity and mortality in young adults. Infections acquired in the hospital setting are one of many risk factors that are associated with higher mortality in this population. Despite significant impact on the overall outcome, infections in TBI patients are largely understudied and underreported. The purpose of this study was to study the profile of infectious complications in patients with TBI and impact of these infections on the hospital outcome of these patients.

Materials and Methods The medical records of all the patients with a diagnosis of TBI admitted in our hospital from January 2017 to January 2020 were reviewed. They were screened for presence of any predefined infection acquired at any time during their hospital stay. Data regarding demographics, focus of infection, results of various cultures, and hospital outcome was recorded.

Results A total of 60 patients with TBI who had developed nosocomial infections were included in this observational study. Patients were mostly young, with a mean age of 36.6 years. Majority (66.6\%) of patients who developed infectious complications had Glasgow coma scale (GCS) score of less than 10 . Respiratory tract and urinary tract were the most common sites of infections in these patients. Burkholderia cepecia and Acinetobacter baumannii were the two most common isolated organisms. Allcause mortality in this population was $23.3 \%$.

Conclusions Most TBI patients are young, in their productive period of lives, and do not have major comorbidities. Invariably, they have low GCS scores and encounter a breach of their surface immunity due to catheters, procedures, and intubation. Such patients make an extremely significant impact on hospital resources as well as poor economic outcomes.
\end{abstract}

published online April 29, 2021
DOI https://doi.org/

$10.1055 / \mathrm{s}-0041-1722829$ ISSN 2277-954X.
(C) 2021. Neurological Surgeons' Society of India.

This is an open access article published by Thieme under the terms of the Creative Commons Attribution-NonDerivative-NonCommercial-License, permitting copying and reproduction so long as the original work is given appropriate credit. Contents may not be used for commercial purposes, or adapted, remixed, transformed or built upon. (https://creativecommons.org/licenses/by-nc-nd/4.0/).

Thieme Medical and Scientific Publishers Pvt. Ltd. A-12, 2nd Floor, Sector 2, Noida-201301 UP, India 


\section{Introduction}

Traumatic brain injury (TBI) is one of the leading causes of morbidity and mortality all over the world. Approximately 50 million cases of TBI are recorded annually all over the world and it contributes to approximately $30 \%$ of all injury-related deaths. ${ }^{1-4}$

Most patients with moderate-to-severe TBI require hospitalization, and mortality of such patients may be as high as $40 \%{ }^{5}$ For inpatient TBI-related deaths, multiple risk factors for mortality have been identified, including age, presence of existing comorbidities, hypotension, injury severity, pupillary abnormalities on presentation, and abnormal imaging findings. ${ }^{6}$

Infections are more common in severe TBI and are an independent risk factor for in-hospital death and prolonged length of stay. Increased risk of infections in these patients is due to the increasingly recognized phenomenon of peripheral immunosuppression because of alterations in the innate and adaptive immune systems. ${ }^{7.8}$ Infections commonly occur in the acute phase after TBI; however, they may even affect patients during rehabilitation and chronic recovery phase and are associated with poorer outcomes overall. ${ }^{9}$

Despite significant impact on the overall outcome, infections in TBI patients are largely understudied and underreported. The purpose of this study was to study the profile of infectious complications in patients with TBI and impact of these infections on the hospital outcome of these patients.

\section{Materials and Methods}

It was a hospital-based observational retrospective study jointly conducted by the Infectious Diseases Division of the Department of Internal Medicine and Neurosurgery Department of Sher-i-Kashmir Institute of Medical Sciences (SKIMS) Srinagar, Kashmir, a leading tertiary care institute in north India.

The medical records of the all the patients with a diagnosis of TBI admitted via emergency department of the hospital from January 2017 to January 2020 were reviewed. These medical records were screened for presence of any predefined infection (defined by latest CDC criteria ${ }^{10}$ ) acquired at any time during their hospital stay. Patients who had evidence of any nosocomial infection were included in the study.

For each included patient, the following data was collected and entered on a standard form: age, gender, days of hospital stay, mode of trauma, type of injury, Glasgow coma scale (GCS) score at the time of presentation, comorbidities, focus of infection, results of cultures, antibiotic sensitivity of isolated organism, results of common laboratory tests, and hospital outcome in terms of all-cause mortality.

The recorded data was compiled and entered in a spreadsheet (Microsoft Excel) and then exported to data editor of SPSS Version 20.0 (SPSS Inc., Chicago, Illinois, USA). Continuous variables were expressed as mean \pm SD and categorical variables were summarized as frequencies and percentages.

\section{Results}

A total of 60 patients were included in 3-year study period. The mean age of patients was 36.6 ( \pm SD 12.3) years. As much as $75 \%$ of the patients were males and $25 \%$ were females. Mean hospital stay of the patients was 10.3 ( \pm SD 5.9) days. Fortythree patients had road traffic accident (RTA) as the cause of TBI, while 17 patients sustained injuries because of a fall.

Subdural hemorrhage was the predominant type of injury in these patients, followed by subarachnoid hemorrhage (SAH), as shown in - Table 1.

The average GCS score of study patients was 9.6. Nine patients had a GCS of less than 7, 31 patients had GCS from 8 to 10 , and 20 patients had GCS score of 11 or above.

The respiratory tract was the predominant focus of infection in these patients, followed by urinary tract, as is shown in - Table 2.

A total of $28(46.6 \%)$ patients had a positive blood culture and 13 (21.6\%) patients had positive urine cultures.

- Tables 3 and 4 show the microbiology of positive blood and urine cultures.

A higher rate of antimicrobial resistance among different Gram-positive organisms was found in our study.

Table 1 Type of injury in study population

\begin{tabular}{|l|l|l|}
\hline Type of injury & Frequency & Percentage \\
\hline Subdural hematoma & 24 & 40.0 \\
\hline Subarachnoid hemorrhage & 14 & 23.3 \\
\hline Brain contusions & 11 & 18.3 \\
\hline Extradural hematoma & 8 & 13.3 \\
\hline Intraparenchymal hemorrhage & 3 & 5.0 \\
\hline Intraventricular hemorrhage & 2 & 3.3 \\
\hline Diffuse axonal injury & 1 & 1.6 \\
\hline
\end{tabular}

Table 2 Focus of infection in study patients

\begin{tabular}{|l|l|l|}
\hline Focus & Frequency & Percentage \\
\hline Respiratory tract & 49 & 81.6 \\
\hline Urinary tract & 13 & 21.6 \\
\hline Skin and soft tissue & 09 & 15.0 \\
\hline $\begin{array}{l}\text { Primary blood } \\
\text { stream }\end{array}$ & 08 & 13.3 \\
\hline others & 03 & 5.0 \\
\hline
\end{tabular}

Table 3 Microbiology of positive blood cultures

\begin{tabular}{|l|l|l|}
\hline Organism & Frequency & $\begin{array}{l}\text { Percentage } \\
\text { (of total patients) }\end{array}$ \\
\hline Burkholderia cepecia & 11 & 18.3 \\
\hline Acinetobacter baumannii & 7 & 11.6 \\
\hline Klebsiella pneumoniae & 4 & 6.6 \\
\hline Staphylococcus aureus & 3 & 5.0 \\
\hline Enterococcus sps & 2 & 3.3 \\
\hline Escherichia coli & 1 & 1.6 \\
\hline
\end{tabular}


- Table 5 shows the sensitivity of different bacterial isolates to commonly used antimicrobials.

Fourteen patients out of the total study cohort died during the hospital stay, thus constituting an all-cause hospital mortality of $23.3 \%$ in these patients.

\section{Discussion}

This study has provided important glimpses about the different types of infections seen early in the hospital course of patients admitted with TBI. Most of these patients are young and tend to have a prolonged hospital stay. Our study demonstrated that majority of patients who develop hospital-acquired infection early in their course of illness had a low GCS score, thereby reaffirming the fact that more severe TBI is associated with more chances of developing nosocomial infections. We do believe that for prevention of infection, natural immunity as well as barrier immunity has utmost importance. The lower the GCS score at admission of a traumatic patient, more vulnerability to infections.

Pulmonary infections were most found to be most common, comprising more than 80 percent of total cases. Previous works by Helling et $\mathrm{al}^{11}$ and Kourbeti et $\mathrm{al}^{12,13}$ also found that pulmonary infections were most common in patients with head trauma. Multiple factors are responsible for development of respiratory tract infections in these patients, which include colonization of lower respiratory tract with microorganisms, continuous microaspirations and subsequent overwhelming of lung defense mechanisms, and frequent use of endotracheal intubation and mechanical

Table 4 Microbiology of positive urine cultures

\begin{tabular}{|l|l|l|}
\hline Organism & Frequency & $\begin{array}{l}\text { Percentage } \\
\text { (of total patients) }\end{array}$ \\
\hline Escherichia coli & 6 & 10.0 \\
\hline $\begin{array}{l}\text { Klebsiella } \\
\text { pneumoniae }\end{array}$ & 3 & 5.0 \\
\hline Enterococcus sps & 3 & 5.0 \\
\hline $\begin{array}{l}\text { Acinetobacter } \\
\text { baumannii }\end{array}$ & 1 & 1.6 \\
\hline
\end{tabular}

ventilation in these patients. ${ }^{14,15}$ In addition, it has been studied earlier that dampening of cough reflex, as is expected in low GCS patients, constitutes the single most important factor in breaching of host defenses for development of infections in traumatic brain patients. A less emphasized fact in such patients is reflux of gastrointestinal (GI) sections into respiratory tract makes a nidus for percolation of infections. An added factor being dampening of secretions due to impaired swallowing in low GCS patients changes the ecobiology of oropharynx and thereby predisposes such patients to infections. ${ }^{15}$

Majority of the patients with moderate to severe TBI require catheterization and are at risk of developing urinary tract infections. Our study demonstrated that urinary tract infections were the second most common nosocomial infections, which is in concordance with previously published literature in trauma patients. ${ }^{16}$ TBI patients often have associated peripheral injuries, and these open wounds provide additional access routes of infection in these patients. Our study showed that skin and soft-tissue infections were common in these patients and comprised $15 \%$ of total infections. Many of these patients develop retention of urine due to neurologic dysfunction, and retained urine becomes a source of infection in some percentage of patients.

This study has also provided important insights into local trends and microbiological agents of infection in these patients. In our study, Burkholderia cepecia and Acinetobacter baumannii were predominant isolates from blood; this is in contrast with a previously published study on such patients wherein coagulase-negative Staphylococcus and S. aureus were more frequent. ${ }^{17}$

The blood stream infections are most of the times neglected in such cohort of patients, but it should be meticulously sought. The present study provides us an insight that Gram-negative organisms predominate blood infections in such patients at our center as against Gram-positive infections seen in such patients in Western countries.

Furthermore, the antibiotic sensitivity profile of these organisms demonstrates that they are less susceptible to commonly used antibiotics, which is an alarming trend. This changing trend of organisms and their resistance pattern

Table 5 Sensitivity of different microorganisms to commonly used antibiotics

\begin{tabular}{|l|l|l|l|l|l|l|l|l|l|}
\hline Organism & $\begin{array}{l}\text { No. of } \\
\text { isolates }\end{array}$ & \multicolumn{6}{|c|}{ Percentage of organisms sensitive to particular antibiotic } \\
\cline { 3 - 9 } & & $\begin{array}{l}\text { Pipercillin/ } \\
\text { tazobactam (\%) }\end{array}$ & $\begin{array}{l}\text { Levofloxacin } \\
(\%)\end{array}$ & $\begin{array}{l}\text { Ceftriaxone } \\
(\%)\end{array}$ & Meropenem & $\begin{array}{l}\text { Vancomycin } \\
(\%)\end{array}$ & $\begin{array}{l}\text { Linizolid } \\
(\%)\end{array}$ & $\begin{array}{l}\text { Amikacin } \\
(\%)\end{array}$ & $\begin{array}{l}\text { Polymyxin } \\
\text { B (\%) }\end{array}$ \\
\hline Burkholderia cepecia & 11 & 45.4 & 27.2 & 18.1 & 90.9 & - & - & 63.6 & 100.0 \\
\hline $\begin{array}{l}\text { Acinetobacter } \\
\text { baumannii }\end{array}$ & 8 & 25 & 12.5 & 12.5 & 50.0 & - & - & 37. & 100.0 \\
\hline $\begin{array}{l}\text { Klebsiella } \\
\text { pneumoniae }\end{array}$ & 7 & 28.5 & 14.2 & 0.0 & 28.5 & - & - & 57.1 & 100.0 \\
\hline $\begin{array}{l}\text { Staphylococcus } \\
\text { aureus }\end{array}$ & 4 & 0.0 & 0.0 & 0.0 & 25.0 & 100.0 & 100.0 & - \\
\hline Enterococcus sps & 5 & 40.0 & 0.0 & 0.0 & 20.0 & 80.0 & 100.0 & - \\
\hline Escherichia coli & 7 & 28.4 & 14.2 & 14.2 & 71.4 & - & - & 85.7 & 100.0 \\
\hline
\end{tabular}


may be attributed to the ubiquitous nature of these in hospital settings and inadequate infection control practices in this part of the world. Rational use of antibiotics and formulation of antibiotic policy, based on changing trend of identified isolates, is urgently needed for this group of patients, so as to improve their overall outcome.

Infections are associated with increased mortality, financial liability, and poor outcome in patients admitted with traumatic injuries. Prevention of many hospital-acquired conditions by implementing interventions aiming to decrease the incidence of hospital-acquired infections may have a better outcome in traumatic brain patients. Further, larger studies need to be done in order to find the mitigation factors, their application, and resultant outcome of application of such practices for better survival of traumatic patients.

\section{Conclusions}

Patients with TBI are more susceptible to develop hospitalacquired infection; more severe TBI, as demonstrated by low GCS score, poses more risk of infection. Respiratory tract and urinary tract are the most common sites of infections in these patients and Gram-negative antibiotic resistant organisms are more frequently involved in this part of the world. Prompt recognition and effective antimicrobial therapy are key to improve hospital outcome in these patients.

\section{Limitations}

Small sample size and retrospective nature were major limitations in our study. Lack of a control group of patients with TBI without infection, missing data regarding exact timing of acquisition of infection during the hospital stay, and lack of follow-up of these patients were some other limitations.

\section{Funding \\ None. \\ Conflict of interest \\ None declared.}

\section{References}

1 de la Tremblaye PB, O'Neil DA, LaPorte MJ, et al. Elucidating opportunities and pitfalls in the treatment of experimental traumatic brain injury to optimize and facilitate clinical translation. Neurosci Biobehav Rev 2018;85:160-175

2 Maas AIR, Menon DK, Adelson PD, et al; InTBIR Participants and Investigators. Traumatic brain injury: integrated approaches to improve prevention, clinical care, and research. Lancet Neurol 2017;16(12):987-1048

3 Taylor CA, Bell JM, Breiding MJ, Xu L. Traumatic brain injury-related emergency department visits, hospitalizations, and deaths - United States, 2007 and 2013. MMWR Surveill Summ 2017;66(9):1-16

4 Thurman DJ, Alverson C, Dunn KA, Guerrero J, Sniezek JE. Traumatic brain injury in the United States: a public health perspective. J Head Trauma Rehabil 1999;14(6):602-615

5 Amoo M, O'Halloran PJ, Leo AM, O'Loughlin A, Mahon P, Lim C. Outcomes of emergency neurosurgical intervention in neuro-critical care patients with traumatic brain injury at Cork University Hospital. Br J Neurosurg 2018;32(6):585-589

6 Utomo WK, Gabbe BJ, Simpson PM, Cameron PA. Predictors of in-hospital mortality and 6-month functional outcomes in older adults after moderate to severe traumatic brain injury. Injury 2009;40(9):973-977

7 Wolach B, Sazbon L, Gavrieli R, Broda A, Schlesinger M. Early immunological defects in comatose patients after acute brain injury. J Neurosurg 2001;94(5):706-711

8 Hazeldine J, Naumann DN, Toman E, et al. Prehospital immune responses and development of multiple organ dysfunction syndrome following traumatic injury: A prospective cohort study. PLoS Med 2017;14(7):e1002338

9 Glance LG, Stone PW, Mukamel DB, Dick AW. Increases in mortality, length of stay, and cost associated with hospital-acquired infections in trauma patients. Arch Surg 2011;146(7):794-801

10 Horan TC, Andrus M, Dudeck MA. CDC/NHSN surveillance definition of health care-associated infection and criteria for specific types of infections in the acute care setting. Am J Infect Control 2008;36(5):309-332

11 Helling TS, Evans LL, Fowler DL, Hays LV, Kennedy FR. Infectious complications in patients with severe head injury. J Trauma 1988;28(11):1575-1577

12 Kourbeti IS, Papadakis JA, Neophytou C, et al. Infections in patients with traumatic brain injury who undergo neurosurgery. Br J Neurosurg 2011;25(1):9-15

13 Kourbeti IS, Vakis AF, Papadakis JA, et al. Infections in traumatic brain injury patients. Clin Microbiol Infect 2012;18(4):359-364

14 Dziedzic T, Slowik A, Szczudlik A. Nosocomial infections and immunity: lesson from brain-injured patients. Crit Care 2004; 8(4):266-270

15 Rello J, Ausina V, Castella J, Net A, Prats G. Nosocomial respiratory tract infections in multiple trauma patients. Influence of level of consciousness with implications for therapy. Chest 1992;102(2):525-529

16 Yadollahi M, Kashkooe A, Feyzi M, Bornapour S. Risk factors of mortality in nosocomial infected traumatic patients in a trauma referral center in south of Iran. Chin J Traumatol 2018;21(5):267-272

17 Dhillon NK, Tseng J, Barmparas G, et al. Impact of early positive cultures in the elderly with traumatic brain injury. J Surg Res 2018;224:140-145 